\title{
Estrutura produtiva do semiárido baiano: uma análise insumo-produto
}

\author{
Carolina Silva Ribeiro ${ }^{1}$ \\ Roberto Maximiano Pereira ${ }^{2}$ \\ Gilca Garcia de Oliveira ${ }^{3}$
}

\begin{abstract}
Resumo: O objetivo deste estudo é analisar a estrutura produtiva do semiárido baiano em 2015 e contribuir para a elaboração de políticas públicas que fomentem o seu desenvolvimento. Para tanto, utiliza-se o ferramental insumo-produto para construir a matriz insumo-produto do semiárido baiano, com base na Matriz Bahia 2015. Faz-se um estudo exploratório dos setores de atividades econômicas da região, mediante a utilização de indicadores de insumo-produto como índices de ligações intersetoriais de Rasmussen-Hirschman, setor-chave, campo de influência e multiplicadores econômicos de produção, emprego e renda. A análise mostrou que sete setores são de grande importância para a região - outros da indústria extrativa; alimentos, bebidas e fumo; têxtil, vestuário e artigos de couros; produtos químicos diversos; indústria da borracha e do plástico; metalurgia e siderurgia; eletricidade, gás, água, esgoto e limpeza urbana -, atuando como demandantes de insumos e ofertantes de produtos. Os multiplicadores econômicos mostraram que o setor de álcool e biocombustíveis é o que mais se destaca na produção. Já a administração pública, saúde e educação pública e seguridade social têm maior potencial para gerar empregos formais na economia. Em relação à geração de renda, o setor agrícola tem um peso na região, destacando-se o cultivo de cereais e outras lavouras temporárias. Assim, ao avaliar a estrutura produtiva do semiárido baiano, espera-se contribuir com os agentes envolvidos na tomada de decisão para a elaboração de políticas visando o seu desenvolvimento social e econômico.
\end{abstract}

Palavras-chave: Desenvolvimento. Estrutura produtiva. Matriz insumo-produto. Semiárido baiano.

\section{Productive structure of the Bahian semiarid: an input-output analysis}

\begin{abstract}
The objective of this study is to analyze the productive structure of the Bahian semiarid in 2015 and to contribute to the development of public policies that foster its development. For this purpose, the input-product tooling is used to build the input-product matrix of the Bahian semiarid, based on the Bahia 2015 matrix. An exploratory study of the economic activity sectors of the region is carried out, using input indicators -product as Rasmussen-Hirschman intersectoral link indices, key sector, field of influence and economic multipliers of production, employment and income. The analysis showed that seven sectors are of great importance for the region - others in the extractive industry; food, drinks and tobacco; textiles, clothing and leather articles; various chemical products; rubber and plastic industry; metallurgy and steel; electricity, gas, water, sewage and urban cleaning - acting as demand for inputs and product offerers. Economic multipliers have shown that the alcohol and biofuels sector is the most prominent in production. Public administration, health and public education and social security have the greatest potential to generate formal jobs in the economy. Regarding income generation, the agricultural sector has

\footnotetext{
${ }^{1}$ Economista. Mestre em Economia e doutoranda em Economia pela Universidade Federal da Bahia. E-mail: minacarol@gmail.com.

${ }^{2}$ Economista pela Universidade Federal de Juiz de Fora e Mestre em Economia pela Universidade Federal da Bahia. E-mail: robertompereira@gmail.com.

3 Engenheira Agrônoma. Doutora em Economia Rural pela Universidade Federal de Viçosa. Professora do Programa de Pós-Graduação em Economia, do Programa de Pós-Graduação em Geografia e da Faculdade de Economia da Universidade Federal da Bahia. E-mail: ggo@ufba.br.
} 
a weight in the region, with emphasis on the cultivation of cereals and other temporary crops. Thus, when evaluating the productive structure of the Bahian semiarid region, it is expected to contribute with the agents involved in decision-making for the development of policies aimed at their social and economic development.

Keywords: Bahian semiarid. Development. Input-output matrix. Productive structure.

\section{Introdução}

O semiárido brasileiro caracteriza-se principalmente pela baixa pluviosidade e, por definição, integram essa área municípios com precipitação média anual igual ou inferior a 800 milímetros, índice de aridez de até 0,5 e risco de seca igual ou superior a 60\% (BRASIL, 2018). Pertencem a esse espaço geográfico cidades de nove estados: Alagoas, Bahia, Ceará, Minas Gerais, Paraíba, Pernambuco, Piauí, Rio Grande do Norte e Sergipe. O semiárido compreende mais de 56,46\% do Nordeste (MEDEIROS, S. de S. et al., 2013). No Estado da Bahia mais de $66 \%$ de seu território está localizado na região semiárida (BRASIL, 2018).

O semiárido brasileiro e, por conseguinte, o baiano têm vivido nos últimos anos a pior seca de sua história (BRASIL, 2018). Trata-se de uma região que carece de políticas que estimulem o seu desenvolvimento, de geração de emprego e renda, bem como de ações para auxiliar no convívio com tais características. No estado da Bahia, a irregularidade de chuvas e o alto índice de aridez acentuam as desigualdades no semiárido, uma vez que a agricultura e a pecuária constituem um dos principais meios de sobrevivência. Nesse sentido, a análise da estrutura produtiva da região é de grande importância para a aplicação de políticas públicas que estimulem o desenvolvimento local e diminuam as disparidades regionais existentes.

Utilizando-se o método insumo-produto é possível analisar a interdependência entre os setores da economia do semiárido baiano, seu encadeamento produtivo e os impactos de choques sobre a produção, o emprego e a renda por meio dos multiplicadores de impactos. Não obstante a realização de pesquisas que empregam a referida metodologia para analisar a estrutura produtiva da economia baiana, este trabalho é pioneiro no estudo da estrutura produtiva do semiárido utilizando especificamente o método em questão.

Dessa forma, o objetivo deste artigo é analisar a estrutura produtiva do semiárido baiano, no ano de 2015, e avaliar a importância dos setores de atividades econômicas, a fim de contribuir na elaboração de políticas públicas que fomentem o desenvolvimento local. Para tanto, utiliza-se o ferramental insumoproduto para construir a matriz insumo-produto do semiárido baiano, com base na Matriz Bahia 2015, estimada pelo Grupo de Estudos de Relações Intersetoriais (GERI) da Universidade Federal da Bahia (UFBA). A investigação consiste em um estudo exploratório dos setores de atividades econômicas do Estado e da região semiárida, mediante a utilização de indicadores de insumo-produto como índices de ligações intersetoriais de Rasmussen-Hirschman, setor-chave, campo de influência e multiplicadores econômicos de produção, emprego e renda, de forma a verificar a criação de empregos e a produção econômica. 
Além desta introdução, o presente estudo está dividido em mais cinco seções. A próxima seção apresenta a metodologia utilizada. Em seguida, discutem-se o desenvolvimento regional e a estrutura produtiva. A quarta seção trata do semiárido baiano. Na quinta, discutem-se os resultados encontrados. A última seção traz algumas considerações acerca do trabalho.

\section{Metodologia}

\subsection{O modelo insumo-produto}

O modelo insumo-produto, desenvolvido por Leontief, tem como objetivo fundamental analisar a interdependência entre os setores de uma economia. Consiste em um sistema de equações lineares, em que cada uma representa a distribuição da produção de um setor entre os demais, sob a forma de insumos, e a demanda final, composta pelo consumo das famílias, governo, investimento e exportações.

Esse modelo, apresentado de forma resumida abaixo, busca contabilizar as contribuições de toda a cadeia produtiva para uma dada demanda (MILLER; BLAIR, 2009). Em termos matriciais, o fluxo intersetorial em uma economia pode ser representado por:

$$
x=A x+y
$$

Em que:

$x$ e $y$ são vetores colunas de ordem $(n \times 1)$, com valores, respectivamente, da produção total e da demanda final de cada setor.

$A$ é a matriz de coeficientes técnicos, de ordem $(n \times n)$.

Tratando-se a demanda final como exógena ao sistema, tem-se que:

$$
\begin{aligned}
& (I-A)^{-1}=B \\
& x=B y
\end{aligned}
$$

Em que:

$B=(I-A)^{-1}$ é a matriz inversa de Leontief ou matriz de coeficientes diretos e indiretos, de ordem $(n$ $x n$ ), na qual o elemento bij deve ser interpretado como a produção total do setor $i$ que é necessária para produzir uma unidade de demanda final do setor $j$.

\section{2 Índices de ligação de Rasmussen-Hirschman, setores chave e indice de dispersão}

Com base na matriz inversa de Leontief, $B=(I-A)^{-1}$, é possível mensurar o encadeamento de cada setor específico com o restante da economia, mediante os efeitos para trás e para frente, conhecidos como os índices de ligação Rasmussen - Hirschman, originários dos trabalhos de Rasmussen (1956) e Hirschman (1958). Os índices de ligação para trás quantificam quanto um setor específico demanda de outros setores. Já os índices de ligação para frente revelam quanto o setor em análise é demandado por outros setores da economia. O cálculo desses índices também é encontrado em Guilhoto et al. (2010). Tais índices podem ser representados da seguinte forma: 
Índice de ligação para trás (encadeamento para trás):

$$
U_{j}=\frac{\left(\frac{B_{* j}}{n}\right)}{B_{*}}, \quad j=1,2, \ldots, n
$$

Índice de ligação para frente (encadeamento para frente):

$$
U_{i}=\frac{\left(\frac{B_{* i}}{n}\right)}{B_{*}}, \quad i=1,2, \ldots, n
$$

Onde: $B_{*}$ é a média de todos os elementos de $\mathrm{B} ; B_{* j}$ é a soma de uma coluna j de $\mathrm{B}$; $B_{* i}$ é a soma de uma linha i de $\mathrm{B}$; $n$ é o número de setores da economia.

Os índices têm a unidade (1) como valor limite de referência para interpretação. Assim, se o índice de ligação para trás for maior que 1 , significa que o setor em análise tem uma forte dependência dos demais setores na economia na demanda por insumos. Já se o índice de ligação para frente for maior do que 1, significa que o setor é importante no fornecimento de insumos na economia. Em síntese, conforme Prado (1981), quando: $U_{j}>1$, o setor tem forte poder de encadeamento para trás; $U_{j}<1$, o setor tem fraco encadeamento para trás; $U_{i}>1$, o setor tem forte poder de encadeamento para frente; $U_{i}<1$, o setor tem fraco encadeamento para frente.

Os setores que apresentam, simultaneamente, valores elevados $\left(U_{j}>1 e U_{i}>1\right)$ dos índices de Rasmussen-Hirschman são considerados setores chave para o crescimento da economia porque têm forte relação com os demais. Entretanto, como os valores dos índices de ligação tratam de uma relação entre médias e estas são sensíveis aos extremos, os coeficientes de dispersão propostos por Rasmussen são utilizados de forma conjunta com esses índices.

Coeficiente de dispersão de Rasmussen para trás:

$v_{* j}=\frac{\sqrt{\frac{1}{n-1} \sum_{i=1}^{n}\left[b_{i j}-\frac{1}{n} \sum_{i=1}^{n} b_{i j}\right]^{2}}}{\frac{1}{n} \sum_{i=1}^{n} b_{i j}}, \quad i, j=1,2, \ldots, n$

Coeficiente de dispersão de Rasmussen para frente:

$v_{i *}=\frac{\sqrt{\frac{1}{n-1} \sum_{j=1}^{n}\left[b_{i j}-\frac{1}{n} \sum_{j=1}^{n} b_{i j}\right]^{2}}}{\frac{1}{n} \sum_{j=1}^{n} b_{i j}}, \quad i, j=1,2, \ldots, n$

Esses coeficientes revelam uma medida de variação ou de dispersão, verificando-se o poder de esparramamento do setor sobre os demais setores da economia. Quanto menor o valor do coeficiente, a relação do setor com os demais setores é homogênea, ou seja, o poder de encadeamento é mais espalhado. Por outro lado, valores altos indicam forte vínculo com poucos setores. Logo, os setores considerados chaves são aqueles que apresentam os índices de ligação superiores a um e baixos valores de $v_{* j}$ e $v_{i *}$. 


\subsection{Campos de Influência}

A análise de campos de influência foi desenvolvida por Sonis e Hewings (1989, 1994) como complementar a dos índices de ligação de Rasmussen-Hirschman. Embora estes índices possam avaliar a importância dos setores em termos de seus impactos no sistema como um todo, há uma dificuldade para visualizar os principais elos dentro da economia (GUILHOTO, 2011). Assim, setores que apresentam maiores índices de ligação, tanto para frente, quanto para trás, estariam associados a esses elos.

O conceito de campo de influência mostra como as mudanças nos coeficientes diretos se distribuem no sistema econômico, possibilitando determinar quais relações entre os setores seriam mais importantes dentro do processo produtivo (GUILHOTO, 2011). Sonis e Hewings (1989, 1994) detalham bem esse conceito. Para obter os campos de influência são consideradas as seguintes matrizes:

$A=\left[a_{i j}\right]$, matriz dos coeficientes diretos;

$E=\left[\varepsilon_{i j}\right]$, matriz de variações incrementais nos coeficientes diretos de insumo;

$B=(I-A)^{-1}=\left[b_{i j}\right]$, matriz inversa de Leontief;

$B(\varepsilon)=(I-A-E)^{-1}=\left[b_{i j}(\varepsilon)\right]$, matriz inversa de Leontief após as mudanças.

De acordo com Sonis e Hewings $(1989,1994)$, caso ocorra uma variação pequena e em apenas um coeficiente técnico, isto é, $\varepsilon_{i j}=\varepsilon, i=i_{1}, j=j_{1}$ e $\varepsilon_{i j}=0, i \neq i_{1}, j \neq j_{1}$, o campo de influência dessa variação será aproximado pela seguinte expressão:

$F\left(\varepsilon_{i j}\right)=\frac{\left[B\left(\varepsilon_{i j}\right)-B\right]}{\varepsilon}$

onde $F\left(\varepsilon_{i j}\right)$ é uma matriz $(n \times n)$ do campo de influência do coeficiente $a_{i j}$. Assim, para identificar quais coeficientes técnicos possuem maior campo de influência, associa-se um valor a cada matriz $F\left(\varepsilon_{i j}\right)$, dado por:

$S_{i j}=\sum_{k=1}^{n} \sum_{l=1}^{n}\left[f_{k l}\left(\varepsilon_{i j}\right)\right]^{2}$

Dessa forma, os maiores valores de $S_{i j}$ indicam os setores que possuem maior campo de influência na economia de maneira geral. Logo, pode-se identificar as relações setoriais que promovem maiores impactos na economia.

\subsection{Multiplicadores}

Por meio da matriz inversa de Leontief $(B)$, é possível calcular os multiplicadores para cada setor da economia. Os multiplicadores permitem estimar, com base em um aumento na demanda final, o impacto direto e indireto de cada setor da economia sobre os empregos, a renda, as importações, o valor adicionado, entre outros (GUILHOTO, 2011). Os multiplicadores auxiliam tanto no processo de tomada 
de decisão de políticas de desenvolvimento, como é o caso do multiplicador de emprego, quanto como indicador de crescimento, no caso do multiplicador de produção.

O multiplicador de produção, que indica quanto se produz para cada unidade monetária gasta no consumo final, é definido da seguinte forma:

$M P_{j}=\sum_{i=1}^{n} b_{i j}$

Sendo $M P_{j}$ o multiplicador de produção do jésimo setor e $b_{i j}$ é o $i j$-ésimo elemento da matriz inversa de Leontief.

Já o multiplicador de emprego indica a quantidade de empregos criados, direta e indiretamente, para cada emprego direto criado e é definido pela expressão:

$M E_{j}=\sum_{i=1}^{n} b_{i j} e_{i}$

em que $e_{i=\frac{E_{i}}{V B P_{i}}}$ representa a razão entre o total de empregados e o valor bruto da produção no setor $i$.

De forma análoga, encontra-se o multiplicador de renda através da razão entre o valor adicionado e o valor bruto da produção, ou seja:

$M V_{j}=\sum_{i=1}^{n} b_{i j} v_{i}$

em que $v_{i=} \frac{V A_{i}}{V B P_{i}}$

\subsection{Base de dados}

A construção da Matriz Insumo-Produto para o semiárido baiano, em 2015, tornou-se possível devido à Matriz Bahia 2015, elaborada pelo GERI-UFBA, com base na Tabela de Recursos e Usos (TRU) 2012 e dos vetores de Consumo Intermediário e Valor Bruto de Produção dos setores de atividades para 2015. Por meio da metodologia RAS, originalmente descrita por Stone (1962) e Bacharach (1970), modificada por Silveira (1993), chegou-se à Matriz Bahia 2015. Com base nesta e com proxies de dados de remuneração dos trabalhadores por município e classe da Classificação Nacional de Atividades Econômicas (CNAE) 2.0 do Relatório Anual de Informações Sociais do Ministério do Trabalho e Emprego (RAIS/MTE) para 2015, foi possível a extrapolação da matriz para o semiárido na Bahia, utilizando a mesma metodologia de Leite (2009).

No processo de construção e regionalização das matrizes do semiárido, as bases trabalhadas foram: o PIB Municipal Bahia 2015 por setor de atividade (agricultura, comércio e serviços, indústria e administração pública); o PIB Municipal 2015 dos municípios dentro e fora do semiárido; o RAIS, com a divisão da CNAE 2.0 por tamanho do estabelecimento (agricultura familiar, micro, pequeno, médio e 
grande).

\section{Desenvolvimento regional e estrutura produtiva}

Os grandes desequilibrios regionais fazem com que regiões desenvolvidas coexistam com outras carentes, do ponto de vista de infraestrutura básica, como é o caso do semiárido baiano. O desenvolvimento econômico não ocorre de maneira uniforme e simultânea em todos os lugares. Assim, várias teorias buscam explicar a dinâmica regional como, por exemplo: Polos de Crescimento, de François Perroux (1967;1975); Causação Circular Cumulativa, de Gunnar Myrdal (1957); Efeitos de Encadeamento Produtivos de Albert Hirschman (1958). Neste artigo, trata-se, especificamente, das contribuições de Albert Hirschman para o desenvolvimento regional, a fim de compreender a estrutura da economia do semiárido baiano.

Para Hirschman (1958), o desenvolvimento econômico é visto como uma cadeia de desequilíbrios, em que o crescimento econômico se manifesta em setores líderes e transfere-se para setores satélites de maneira desequilibrada. "Alcança-se uma situação ideal quando um desequilibrio provoca um movimento desenvolvimentista que, por seu turno, cria um desequilíbrio similar e assim por diante ad infinitum" (HIRSCHMAN, 1958, p. 115). Com isso, e baseado na proposta de Rasmussen (1956) de avaliar a estrutura da economia por meio do cálculo de índices de encadeamento que captassem os efeitos intersetoriais e intrasetoriais na economia, Hirschman (1958) chega às ideias de "mecanismo indutor" e de "poder de encadeamento". Ribeiro (2010) afirma que a indução do crescimento se daria na estrutura da economia através seus efeitos intrassetoriais, e que o melhor aproveitamento desses efeitos dependeria do poder de encadeamento de cada setor sobre os demais. Nesse sentido, a análise do encadeamento produtivo do semiárido auxiliaria no direcionamento de políticas específicas para o desenvolvimento local da referida região.

De acordo com Guilhoto (2011), as análises estruturais buscam compreender como a economia funciona e como os setores e as regiões interagem entre si. Entre as técnicas utilizadas nas análises estruturais estão os índices de Rasmussen-Hirschman, a determinação dos setores chave e o conceito de campo de influência, desenvolvido por Sonis e Hewings $(1989,1994)$, que serão detalhados na Seção 5. Através das análises de impacto, é possível estudar a reação da economia e de seus setores a choques resultantes de políticas econômicas e/ou de alterações de comportamento dos agentes econômicos (GUILHOTO, 2011). Assim, conforme esse autor, a possibilidade de medir os impactos das variações na demanda final sobre algumas variáveis do sistema econômico torna os indicadores de insumo-produto instrumentos importantes para a elaboração de estratégias de crescimento e desenvolvimento.

Entre os estudos de análise estrutural e de impactos realizados para a economia baiana, estão o de Perobelli et al. (2015), que estimam uma matriz insumo-produto para a Bahia, tendo como ano base 2009, para, por meio desta, evidenciar características sistêmicas da estrutura produtiva do Estado. A matriz apresenta abertura setorial para vinte e sete atividades econômicas. Os resultados apontaram a importância da indústria petroquímica e do setor de serviços. Os autores também observaram que várias atividades da 
economia baiana estavam pouco integradas à cadeia produtiva do Estado. Outro destaque é o trabalho de Gonçalves, Neves e Braga (2014) que, com base na estrutura da economia baiana de 2011, encontrou resultados semelhantes aos de Perobelli et al. (2015). Leite e Pereira (2010) e Ribeiro e Rocha (2013) também realizaram análises estruturais para o Estado da Bahia. Todos esses estudos permitem compreender as relações entre os setores do Estado, subsidiando a formulação de políticas públicas.

\section{O semiárido baiano}

De forma geral, as regiões semiáridas caracterizam-se pela aridez do clima, deficiência hídrica, imprevisibilidade da precipitação pluviométrica e, na sua grande maioria, por solos pobres em matéria orgânica (SILVA, 2006). A precipitação média está em uma amplitude que varia de 250 a $800 \mathrm{~mm}$ anuais, distribuídos entre três e cinco meses, com elevadas taxas de evapotranspiração (LOPES, 2003). Na maior parte do semiárido, as chuvas esporádicas são as únicas fontes de água para a sobrevivência, visto que a formação geológica que origina o solo é cristalina, com baixo potencial para acumular a água subterrânea (LOPES, 2003). Para mitigar os efeitos da escassez hídrica e auxiliar na convivência com a seca várias cidades do semiárido baiano tem captado água de chuva por meio de tecnologias alternativas (RIBEIRO; OLIVEIRA, 2019).

Com alta biodiversidade, onde se destaca a formação vegetal xerófila com folhas pequenas que reduzem a transpiração e raízes espalhadas para captar o máximo de água durante as chuvas. Cactos e bromélias são, também, elementos importantes da paisagem da caatinga (SILVA, 2006). Cactos e bromélias são, também, elementos importantes da paisagem da caatinga, conforme esse autor.

O Estado da Bahia tem mais de $66 \%$ de seu território dentro do semiárido, isto é, dos 417 municípios existentes, 278 pertencem a essa região, compreendendo uma área de $446.021 \mathrm{~km}^{2}$ (BRASIL, 2018), como pode ser observado na Figura 1. A população residente no semiárido baiano é de aproximadamente 7.675 .656 habitantes (BRASIL, 2018). A maioria da população depende da criação de animais e da agricultura para sobreviver.

No cômputo do Valor Adicionado Bruto (VAB) da agropecuária no Estado, a região foi responsável por 51,4\%, em 2015 (BAHIA, 2016). No entanto, em termos de participação do Produto Interno Bruto (PIB) a preços correntes, o setor de serviços foi o mais representativo, com 40,3\%, contra $11,4 \%$ do setor agropecuário (BAHIA, 2016). A região produziu, em 2015, aproximadamente 33\% do PIB estadual (BAHIA, 2016), conforme Tabela 1. 


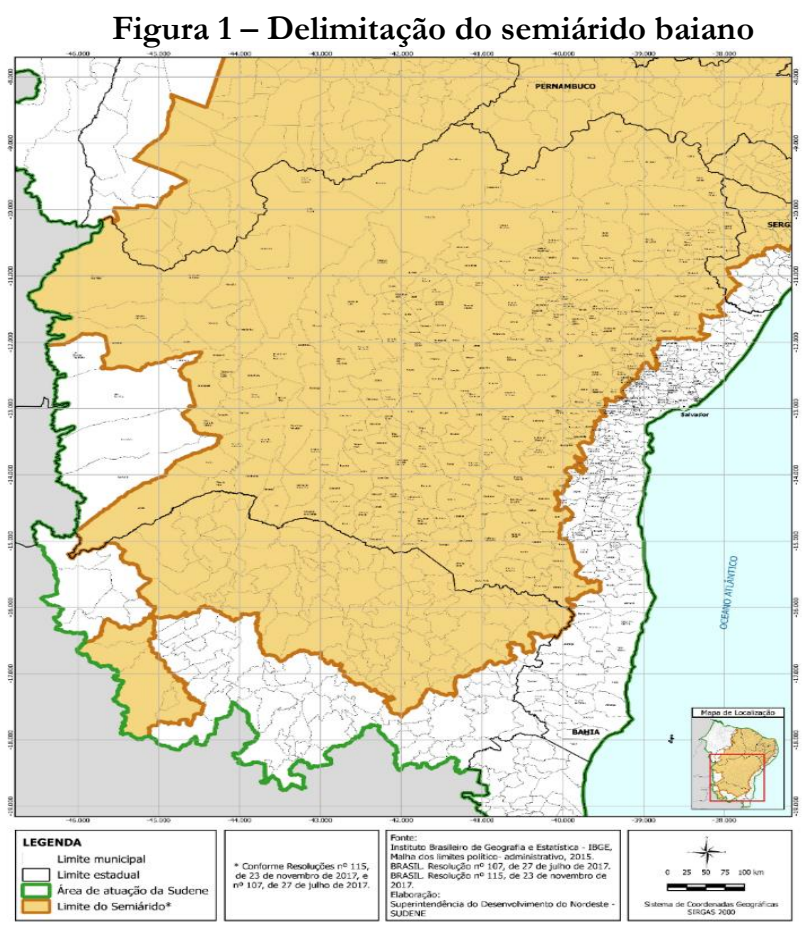

Fonte: SUDENE, 2018.

Tabela 1 - Produto Interno Bruto do semiárido, fora do semiárido e do estado da Bahia, 2015, em bilhões de reais

\begin{tabular}{lrrr}
\hline PIB a preços correntes & Semiárido & Fora do Semiárido & Bahia \\
\hline VAB Agropecuária & 9.166 .444 .882 & 8.669 .368 .973 & 17.835 .813 .855 \\
VAB Indústria & 10.446 .756 .758 & 37.320 .788 .588 & 47.767 .545 .346 \\
VAB Serviços & 32.439 .923 .993 & 73.618 .714 .013 & 106.058 .638 .006 \\
$\begin{array}{l}\text { VAB Administração, defesa, educação e } \\
\text { saúde públicas e seguridade social }\end{array}$ & 21.942 .059 .173 & 22.363 .235 .222 & 44.305 .294 .395 \\
$\begin{array}{l}\text { VAB total } \\
\begin{array}{l}\text { Impostos, líquidos de subsídios, sobre } \\
\text { produtos }\end{array}\end{array}$ & 73.995 .184 .807 & 141.972 .106 .803 & 215.967 .291 .610 \\
PIB & 6.472 .146 .261 & 22.585 .424 .246 & 29.057 .570 .507 \\
\hline Fonte: BAHIA, 2016. & & 164.557 .531 .056 & 245.024 .862 .122 \\
\hline
\end{tabular}

De acordo com Nascimento (2010), no semiárido baiano, uma região marcada por desigualdades sociais e econômicas, concentram-se o maior percentual de estabelecimento da agricultura familiar (77\%) e a maior área com essa modalidade de cultivo da terra $(81,5 \%)$. 


\section{Resultados}

\subsection{Indicadores estruturais}

\subsection{1 Índices de Ligação de Rasmussen-Hirschman e Índice de Dispersão}

Por meio dos coeficientes de ligação de Rasmussen-Hirschman, é possível compreender o poder de encadeamento dos setores em relação à média da economia. Os setores com maior poder de encadeamento são aqueles cujos valores de coeficientes são maiores que um. Já nos índices de dispersão, quanto menor o valor do coeficiente mais o setor se relaciona com muitos setores; valores altos indicam, portanto, vínculo com poucos setores.

Os setores do semiárido baiano com forte encadeamento para trás (Tabela 2) são: álcool e biocombustíveis $(1,77)$; outros equipamentos de transporte $(1,72)$; refino de petróleo $(1,44)$; máquinas e materiais elétricos (1,33); outros produtos minerais não metálicos (1,31); móveis e indústrias diversas $(1,31)$; indústria automotiva e peças para veículos $(1,19)$; produtos farmacêuticos $(1,10)$; cultivo de algodão $(1,09)$; máquinas para escritório, eletrônicos, ópticos e hospitalares $(1,03)$; produção florestal $(1,01)$. O setor de álcool e biocombustíveis é, portanto, o mais homogêneo $(1,73)$.

No que tange às ligações para frente (Tabela 2), destacam-se no fornecimento de insumos para o semiárido: construção civil (2,33); comércio e serviços de manutenção e reparação $(1,98)$; transporte, armazenagem e correios (1,91); atividades imobiliárias e aluguéis (1,57); intermediação financeira e previdência complementar $(1,56)$; serviços prestados às empresas $(1,41)$; máquinas e materiais elétricos $(1,33)$; criação de animais $(1,23)$; serviços de alojamento e alimentação $(1,02)$.

Tabela 2 - Índices de ligações de Rasmussen-Hirschman e índices de dispersão, semiárido baiano, 2015

(continua)

\begin{tabular}{|c|c|c|c|c|c|c|c|c|c|}
\hline & \multirow{2}{*}{ Setores de atividade econômica } & \multicolumn{4}{|c|}{ Índices de Rasmussen-Hirschman } & \multicolumn{4}{|c|}{ Índices de dispersão } \\
\hline & & Frente $(\mathrm{Ui})$ & Rank & Trás $\left(\mathrm{Uj}_{\mathrm{j}}\right)$ & Rank & Frente (Vi) & Rank & Trás $\left(V_{j}\right)$ & Rank \\
\hline 1 & Cultivo de cereais & 0,5242 & $30^{\circ}$ & 0,8277 & $28^{\circ}$ & 5,4025 & $13^{\circ}$ & 3,4262 & $16^{\circ}$ \\
\hline 2 & Cultivo de algodão & 0,9611 & $17^{\circ}$ & 1,0874 & $16^{\circ}$ & 3,0288 & $24^{\circ}$ & 2,7708 & $25^{\circ}$ \\
\hline 3 & Cultivo de cana-de-açúcar & 0,4407 & $40^{\circ}$ & 0,6774 & $34^{\circ}$ & 6,5156 & $1^{\mathrm{o}}$ & 4,2052 & $9^{\circ}$ \\
\hline 4 & Cultivo de soja & 0,9212 & $19^{\circ}$ & 0,935 & $21^{\circ}$ & 3,2105 & $22^{\circ}$ & 3,2264 & $19^{\circ}$ \\
\hline 5 & Outras lavouras temporárias & 0,8915 & $20^{\circ}$ & 0,7726 & $29^{\circ}$ & 3,2913 & $21^{\circ}$ & 3,8705 & $13^{\circ}$ \\
\hline 6 & Cultivo de laranja & 0,4946 & $34^{\circ}$ & 0,5825 & $39^{\circ}$ & 5,8233 & $9^{\circ}$ & 4,9055 & $2^{\circ}$ \\
\hline 7 & Cultivo de café & 0,5144 & $32^{\circ}$ & 0,8829 & $25^{\circ}$ & 5,4799 & $12^{\circ}$ & 3,1813 & $20^{\circ}$ \\
\hline 8 & Outras lavouras permanentes & 0,6232 & $25^{\circ}$ & 0,6185 & $37^{\circ}$ & 4,5806 & $16^{\circ}$ & 4,6129 & $6^{\circ}$ \\
\hline 9 & Criação de animais & 1,2287 & $13^{\circ}$ & 0,7445 & $30^{\circ}$ & 2,4693 & $27^{\circ}$ & 4,1872 & $11^{\circ}$ \\
\hline 10 & Produção florestal & 0,5678 & $28^{\circ}$ & 1,0123 & $19^{\circ}$ & 5,9419 & $7^{\circ}$ & 3,3093 & $17^{\circ}$ \\
\hline
\end{tabular}




\section{Tabela 2 - Índices de ligações de Rasmussen-Hirschman e índices de dispersão, semiárido} baiano, 2015

(conclusão)

\begin{tabular}{|c|c|c|c|c|c|c|c|c|c|}
\hline & \multirow{2}{*}{ Setores de atividade econômica } & \multicolumn{4}{|c|}{ Índices de Rasmussen-Hirschman } & \multicolumn{4}{|c|}{ Índices de dispersão } \\
\hline & & Frente (Ui) & Rank & Trás $\left(\mathrm{Uj}_{\mathrm{j}}\right)$ & Rank & Frente (Vi) & Rank & Trás $\left(V_{j}\right)$ & Rank \\
\hline 11 & Extração de petróleo e gás natural & - & - & - & - & - & - & - & - \\
\hline 12 & Outros da indústria extrativa & 1,4052 & $10^{\circ}$ & 1,4558 & $4^{\circ}$ & 2,399 & $29^{\circ}$ & 2,3888 & $32^{\circ}$ \\
\hline 13 & Alimentos, bebidas e fumo & 1,7081 & $5^{\circ}$ & 1,1683 & $13^{\circ}$ & 2,3417 & $30^{\circ}$ & 3,5234 & $15^{\circ}$ \\
\hline 14 & Têxtil, vestuário e artigos de couros & 1,3139 & $12^{\circ}$ & 1,1976 & $10^{\circ}$ & 2,1811 & $32^{\circ}$ & 2,4764 & $29^{\circ}$ \\
\hline 15 & Celulose, papel, jornais, revistas e discos & 0,9884 & $16^{\circ}$ & 0,9936 & $20^{\circ}$ & 2,8289 & $25^{\circ}$ & 2,9221 & $23^{\circ}$ \\
\hline 16 & Refino de petróleo & 0,4888 & $35^{\circ}$ & 1,4377 & $5^{\circ}$ & 6,1622 & $5^{\circ}$ & 2,0812 & $38^{\circ}$ \\
\hline 17 & Álcool e biocombustíveis & 0,5227 & $31^{\circ}$ & 1,7678 & $1^{\mathrm{o}}$ & 5,8547 & $8^{\circ}$ & 1,734 & $40^{\circ}$ \\
\hline 18 & Produtos químicos diversos & 1,5206 & $8^{\circ}$ & 1,0258 & $18^{\circ}$ & 1,7768 & $35^{\circ}$ & 2,8129 & $24^{\circ}$ \\
\hline 19 & Perfumaria, higiene e limpeza & 0,464 & $36^{\circ}$ & 1,477 & $2^{\circ}$ & 6,1751 & $4^{\circ}$ & 1,9536 & $39^{\circ}$ \\
\hline 20 & Produtos farmacêuticos & 0,4546 & $38^{\circ}$ & 1,1043 & $15^{\circ}$ & 6,1065 & $6^{\circ}$ & 2,5158 & $28^{\circ}$ \\
\hline 21 & Industria da borracha e do plástico & 1,3436 & $11^{\circ}$ & 1,3566 & $6^{\circ}$ & 2,2763 & $31^{\circ}$ & 2,3453 & $33^{\circ}$ \\
\hline 22 & Outros produtos minerais não metálicos & 0,8756 & $21^{\circ}$ & 1,3089 & $9^{\circ}$ & 3,386 & $20^{\circ}$ & 2,3131 & $34^{\circ}$ \\
\hline 23 & Metalurgia e siderurgia & 1,2215 & $14^{\circ}$ & 1,4567 & $3^{\circ}$ & 2,4191 & $28^{\circ}$ & 2,1174 & $37^{\circ}$ \\
\hline 24 & $\begin{array}{l}\text { Máq. para escritório, eletrônicos, ópticos e } \\
\text { hospitalar }\end{array}$ & 0,4428 & $39^{\circ}$ & 1,0349 & $17^{\circ}$ & 6,3877 & $2^{\circ}$ & 2,7664 & $26^{\circ}$ \\
\hline 25 & Máquinas e materiais elétricos & 0,7997 & $23^{\circ}$ & 1,3296 & $7^{\circ}$ & 3,5647 & $18^{\circ}$ & 2,1875 & $35^{\circ}$ \\
\hline 26 & Máquinas e equipamentos e manutenção & 0,6605 & $24^{\circ}$ & 0,8627 & $26^{\circ}$ & 4,2353 & $17^{\circ}$ & 3,2739 & $18^{\circ}$ \\
\hline 27 & Industria automotiva e peças para veículos & 0,4953 & $33^{\circ}$ & 1,1942 & $11^{\circ}$ & 5,7395 & $10^{\circ}$ & 2,404 & $31^{\circ}$ \\
\hline 28 & Outros equipamentos de transporte & 0,4555 & $37^{\circ}$ & 1,1726 & $12^{\circ}$ & 6,2581 & $3^{\circ}$ & 2,4323 & $30^{\circ}$ \\
\hline 29 & Móveis e indústrias diversas & 0,558 & $29^{\circ}$ & 1,3143 & $8^{\circ}$ & 5,022 & $14^{\circ}$ & 2,1313 & $36^{\circ}$ \\
\hline 30 & $\begin{array}{l}\text { Eletricidade, gás, água, esgoto e limpeza } \\
\text { urbana }\end{array}$ & 2,4184 & $1^{\circ}$ & 1,1244 & $14^{\circ}$ & 1,1628 & $40^{\circ}$ & 2,7537 & $27^{\circ}$ \\
\hline 31 & Construção civil & 2,3288 & $2^{\circ}$ & 0,9006 & $24^{\circ}$ & 1,3982 & $38^{\circ}$ & 3,8946 & $12^{\circ}$ \\
\hline 32 & $\begin{array}{l}\text { Comércio e serviços de manutenção e } \\
\text { reparação }\end{array}$ & 1,9806 & $3^{\circ}$ & 0,6552 & $36^{\circ}$ & 1,3792 & $39^{\circ}$ & 4,5076 & $7^{\circ}$ \\
\hline 33 & Transporte, armazenagem e correios & 1,9097 & $4^{\circ}$ & 0,8297 & $27^{\circ}$ & 1,4731 & $37^{\circ}$ & 3,6439 & $14^{\circ}$ \\
\hline 34 & Serviços de alojamento e alimentação & 1,0207 & $15^{\circ}$ & 0,9274 & $22^{\circ}$ & 2,7413 & $26^{\circ}$ & 3,1029 & $22^{\circ}$ \\
\hline 35 & Serviços de informação & 0,8066 & $22^{\circ}$ & 0,9054 & $23^{\circ}$ & 3,4864 & $19^{\circ}$ & 3,1724 & $21^{\circ}$ \\
\hline 36 & $\begin{array}{l}\text { Intermediação financeira e prev. } \\
\text { complementar }\end{array}$ & 1,56 & $7^{\circ}$ & 0,7196 & $31^{\circ}$ & 2,1318 & $33^{\circ}$ & 4,8111 & $3^{\circ}$ \\
\hline 37 & Atividades imobiliárias e aluguéis & 1,5664 & $6^{\circ}$ & 0,5032 & $40^{\circ}$ & 1,7757 & $36^{\circ}$ & 5,8146 & $1^{\circ}$ \\
\hline 38 & Serviços prestados às empresas & 1,4126 & $9^{\circ}$ & 0,6835 & $33^{\circ}$ & 1,9439 & $34^{\circ}$ & 4,2017 & $10^{\circ}$ \\
\hline 39 & $\begin{array}{l}\text { Adm. púb., saúde e educ. púb. e seguridade } \\
\text { social }\end{array}$ & 0,9213 & $18^{\circ}$ & 0,6016 & $38^{\circ}$ & 3,0749 & $23^{\circ}$ & 4,7833 & $4^{\circ}$ \\
\hline 40 & Saúde e educação mercantil & 0,5929 & $27^{\circ}$ & 0,6836 & $32^{\circ}$ & 5,5131 & $11^{\circ}$ & 4,7571 & $5^{\circ}$ \\
\hline 41 & Serviços prestados às famílias & 0,5959 & $26^{\circ}$ & 0,6667 & $35^{\circ}$ & 4,8782 & $15^{\circ}$ & 4,349 & $8^{\circ}$ \\
\hline
\end{tabular}

Fonte: Elaborado pelos autores, 2018.

\subsubsection{Setores chave}

Os setores chave, aqueles com índices de ligação maiores que um, do semiárido baiano para o ano de 2015, são apresentados na Tabela 3. Sete deles são considerados chave porque são importantes tanto como demandantes de insumos quanto como ofertantes de produtos: outros da indústria extrativa; 
alimentos, bebidas e fumo; têxtil, vestuário e artigos de couros; produtos químicos diversos; indústria da borracha e do plástico; metalurgia e siderurgia; eletricidade, gás, água, esgoto e limpeza urbana.

Tabela 3 - Setores chave da economia, semiárido baiano, 2015

\begin{tabular}{lrrrr}
\hline \multirow{2}{*}{\multicolumn{1}{c}{ Setores chave }} & \multicolumn{2}{c}{$\begin{array}{c}\text { Índices de Rasmussen- } \\
\text { Hirschman }\end{array}$} & \multicolumn{2}{c}{ Índices de dispersão } \\
\cline { 2 - 5 } & Frente (Ui) & Trás (Uj) & Frente (Vi) & Trás (Vj) \\
\hline Outros da indústria extrativa & 1,4052 & 1,4558 & 2,3990 & 2,3888 \\
Alimentos, bebidas e fumo & 1,7081 & 1,1683 & 2,3417 & 3,5234 \\
Têxtil, vestuário e artigos de couros & 1,3139 & 1,1976 & 2,1811 & 2,4764 \\
Produtos químicos diversos & 1,5206 & 1,0258 & 1,7768 & 2,8129 \\
Industria da borracha e do plástico & 1,3436 & 1,3566 & 2,2763 & 2,3453 \\
Metalurgia e siderurgia & 1,2215 & 1,4567 & 2,4191 & 2,1174 \\
Eletricidade, gás, Água, esgoto e limpeza urbana & 2,4184 & 1,1244 & 1,1628 & 2,7537 \\
\hline
\end{tabular}

Fonte: Elaborado pelos autores, 2018.

\subsubsection{Campos de influência}

A análise dos campos de influência complementa os índices de ligação, mostrando as relações setoriais mais importantes que promovem maiores impactos na economia. Na Figura 2, nas colunas, está a ótica dos setores compradores; nas linhas, a ótica dos setores vendedores. Assim, dos 41 setores de atividades da economia, o setor 29 - móveis e indústrias diversas - e o setor 30 - eletricidade, gás, água, esgoto e limpeza urbana, são os que apresentam maiores efeitos propagadores sobre os demais. Na ótica das vendas há pouca interação.

Figura 2 - Campo de influência do semiárido baiano, 2015

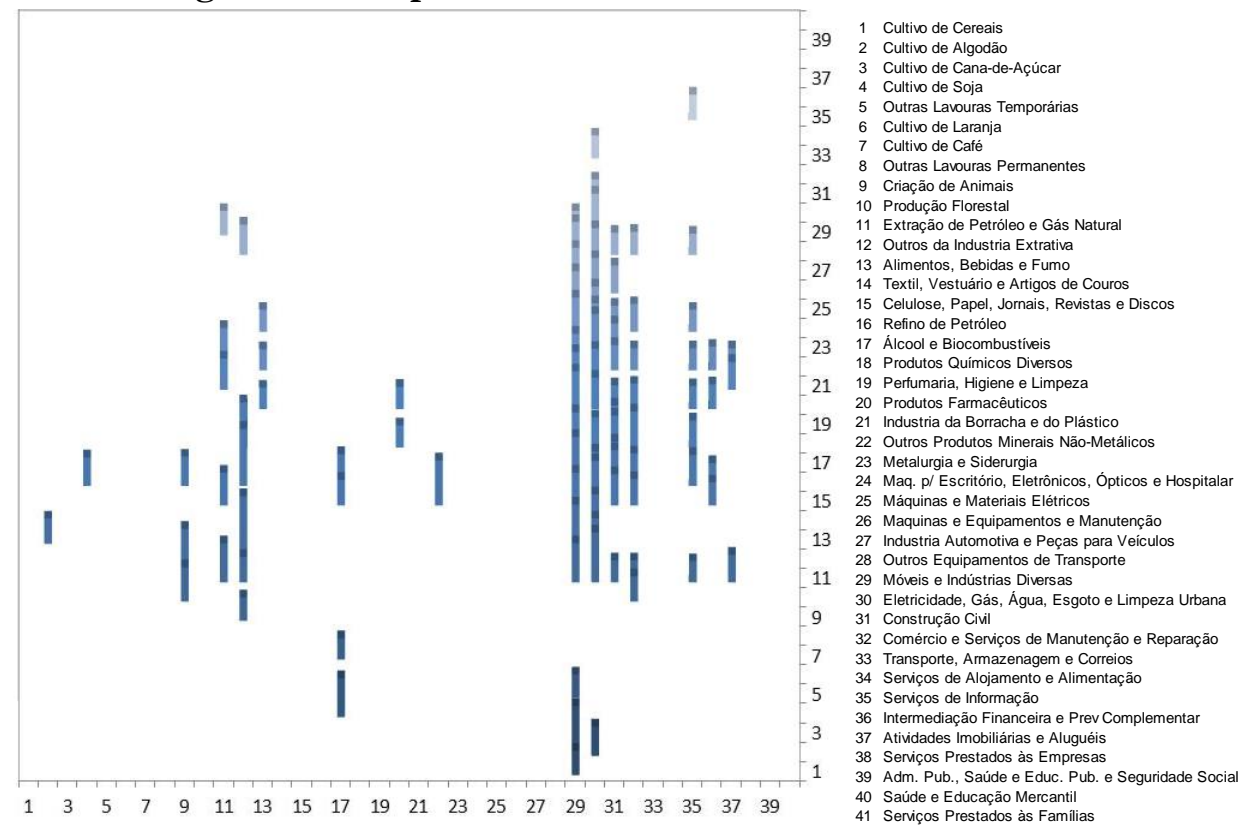

Fonte: Elaborado pelos autores, 2018. 


\subsubsection{Poder de encadeamento e valor adicionado dos setores de atividades}

$\mathrm{Na}$ Figura 3, é possível associar o poder de encadeamento dos setores de atividade do semiárido baiano à magnitude do valor adicionado destes na economia da região. Logo, na Figura 3, o tamanho da bolha representa o tamanho do Valor Adicionado (VA). Em vermelho, está o PIB do setor identificado como negativo em 2015; em verde, estão marcados os setores chave e, em azul, os demais. Observa-se que os setores chave identificados, aqueles com forte poder de encadeamento para frente e para trás, não apresentaram, em 2015, os maiores VAs.

Figura 3 - Índices, setores chave e valor adicionado do semiárido baiano, 2015

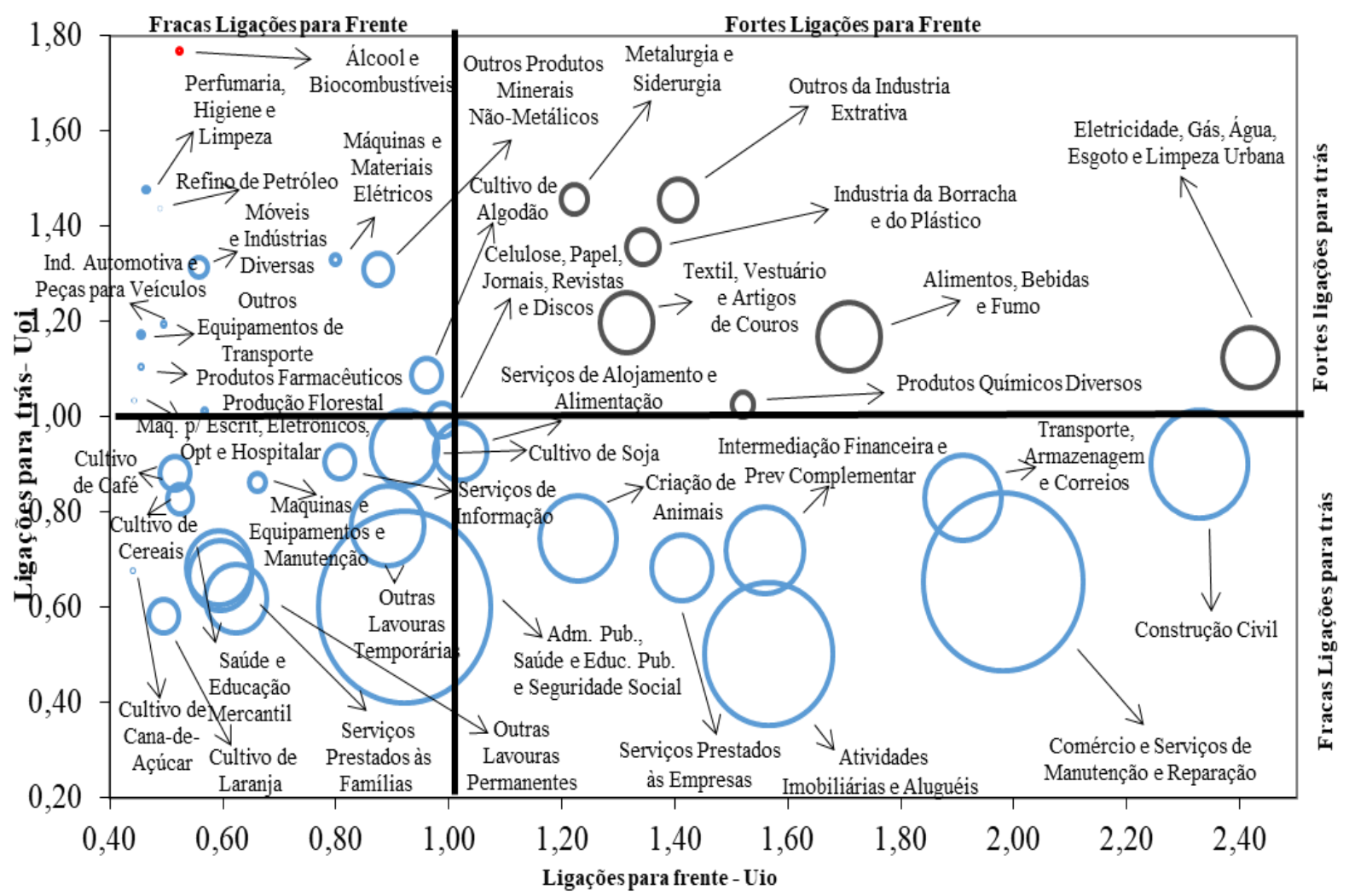

Fonte: Elaborado pelos autores, 2018.

É interessante notar que os setores que concentram VAs elevados são os mesmos que se destacam no fornecimento de insumos para a região, isto é, possuem forte poder de encadeamento para frente. A maioria destes pertencem ao setor de serviços (comércio e serviços de manutenção e reparação; atividades imobiliárias e aluguéis; intermediação financeira e previdência complementar; transporte, armazenagem e correios; serviços prestados às empresas), o que corrobora os dados da Tabela 1 , os quais mostram que o VAB Serviços é o mais representativo na participação do PIB do semiárido. O setor de administração 
pública, saúde e educação pública e seguridade social é o segundo em representatividade no PIB da região e possui franco poder de encadeamento.

\subsection{Indicadores de impacto}

\subsubsection{Multiplicadores de impactos: produção, emprego e renda}

Os multiplicadores de impactos (Tabela 4) mostram, para os setores de atividades no semiárido baiano, para o ano de 2015, os multiplicadores de produção, emprego e renda. O setor de álcool e biocombustíveis possui o maior multiplicador de produção e o pior multiplicador de renda, devido ao fato de, em 2015, seu Valor Adicionado ser negativo. Tal condição significa que os custos (consumo intermediário) foram maiores que o faturamento (valor bruto de produção), gerando não um valor adicionado (lucro do setor), mas um valor negativo (prejuízo do setor).

Tabela 4 - Multiplicadores de impacto do semiárido baiano, 2015

\begin{tabular}{|c|c|c|c|c|c|c|c|}
\hline & \multirow{3}{*}{ Setores de atividade econômica } & \multicolumn{2}{|c|}{ Produção } & \multicolumn{2}{|c|}{ Emprego } & \multicolumn{2}{|c|}{ Renda } \\
\hline & & \multicolumn{2}{|c|}{$\begin{array}{l}\text { Variação unitária - } \\
\qquad(\mathrm{R} \$)\end{array}$} & \multicolumn{2}{|c|}{$\begin{array}{l}\text { Cada } \mathrm{R} \$ 1 \text { milhão } \\
\text { na demanda final }\end{array}$} & \multicolumn{2}{|c|}{$\begin{array}{c}\text { Variação unitária - } \\
(\mathrm{R} \$)\end{array}$} \\
\hline & & $\mathrm{MPj}$ & Rank & Mej & Rank & $\mathrm{MVj}$ & Rank \\
\hline 1 & Cultivo de cereais & 1,9 & $28^{\circ}$ & 8,67 & $20^{\circ}$ & 1,23 & $1^{\circ}$ \\
\hline 2 & Cultivo de algodão & 2,49 & $16^{\circ}$ & 3,34 & $34^{\circ}$ & 0,83 & $27^{\circ}$ \\
\hline 3 & Cultivo de cana-de-açúcar & 1,55 & $34^{\circ}$ & 5,56 & $26^{\circ}$ & 1,08 & $10^{\circ}$ \\
\hline 4 & Cultivo de soja & 2,14 & $21^{\circ}$ & 1,63 & $38^{\circ}$ & 1,06 & $12^{\circ}$ \\
\hline 5 & Outras lavouras temporárias & 1,77 & $29^{\circ}$ & 3,36 & $33^{\circ}$ & 1,2 & $2^{\circ}$ \\
\hline 6 & Cultivo de laranja & 1,34 & $39^{\circ}$ & 1,38 & $40^{\circ}$ & 1,17 & $6^{\circ}$ \\
\hline 7 & Cultivo de café & 2,03 & $25^{\circ}$ & 9,68 & $18^{\circ}$ & 1,14 & $7^{\circ}$ \\
\hline 8 & Outras lavouras permanentes & 1,42 & $37^{\circ}$ & 10,69 & $15^{\circ}$ & 1,13 & $8^{\circ}$ \\
\hline 9 & Criação de animais & 1,71 & $30^{\circ}$ & 7,26 & $23^{\circ}$ & 1,19 & $4^{0}$ \\
\hline 10 & Produção florestal & 2,32 & $19^{\circ}$ & 17,91 & $9^{\circ}$ & 0,54 & $33^{\circ}$ \\
\hline 11 & Extração de petróleo e gás natural & - & - & - & - & - & - \\
\hline 12 & Outros da indústria extrativa & 3,34 & $4^{\circ}$ & 14,35 & $11^{\circ}$ & 0,91 & $22^{\circ}$ \\
\hline 13 & Alimentos, bebidas e fumo & 2,68 & $13^{\circ}$ & 6,9 & $24^{\circ}$ & 0,55 & $31^{\circ}$ \\
\hline 14 & Têxtil, vestuário e artigos de couros & 2,75 & $10^{\circ}$ & 27,09 & $4^{o}$ & 0,96 & $20^{\circ}$ \\
\hline 15 & Celulose, papel, jornais, revistas e discos & 2,28 & $20^{\circ}$ & 7,83 & $21^{\circ}$ & 0,74 & $28^{\circ}$ \\
\hline 16 & Refino de petróleo & 3,3 & $5^{\circ}$ & 1,81 & $37^{\circ}$ & 0,32 & $37^{\circ}$ \\
\hline 17 & Álcool e biocombustíveis & 4,06 & $1^{\circ}$ & 5,12 & $29^{\circ}$ & $-0,39$ & $40^{\circ}$ \\
\hline 18 & Produtos químicos diversos & 2,35 & $18^{\circ}$ & 2,03 & $36^{\circ}$ & 0,47 & $35^{\circ}$ \\
\hline 19 & Perfumaria, higiene e limpeza & 3,39 & $2^{\circ}$ & 31,13 & $2^{\circ}$ & 0,53 & $34^{\circ}$ \\
\hline 20 & Produtos farmacêuticos & 2,53 & $15^{\circ}$ & 20,5 & $7^{\circ}$ & 1,02 & $15^{\circ}$ \\
\hline 21 & Indústria da borracha e do plástico & 3,11 & $6^{\circ}$ & 9,28 & $19^{\circ}$ & 0,65 & $30^{\circ}$ \\
\hline 22 & Outros produtos minerais não metálicos & 3 & $9^{\circ}$ & 26,84 & $5^{\circ}$ & 0,92 & $21^{\circ}$ \\
\hline 23 & Metalurgia e siderurgia & 3,34 & $3^{\circ}$ & 7,37 & $22^{\circ}$ & 0,55 & $32^{\circ}$ \\
\hline 24 & Máq. para escritório, eletrônicos, ópticos e hospitalar & 2,37 & $17^{\circ}$ & 5,14 & $28^{\circ}$ & 0,72 & $29^{\circ}$ \\
\hline 25 & Máquinas e materiais elétricos & 3,05 & $7^{o}$ & 3,64 & $32^{\circ}$ & 0,24 & $39^{\circ}$ \\
\hline 26 & Maquinas e equipamentos e manutenção & 1,98 & $26^{\circ}$ & 5,64 & $25^{\circ}$ & 1,19 & $3^{\circ}$ \\
\hline 27 & Industria automotiva e peças para veículos & 2,74 & $11^{\circ}$ & 12,59 & $12^{\circ}$ & 0,25 & $38^{\circ}$ \\
\hline 28 & Outros equipamentos de transporte & 2,69 & $12^{\circ}$ & 3 & $35^{\circ}$ & 0,46 & $36^{\circ}$ \\
\hline 29 & Móveis e indústrias diversas & 3,01 & $8^{\circ}$ & 28,28 & $3^{\circ}$ & 1,18 & $5^{\circ}$ \\
\hline 30 & Eletricidade, gás, água, esgoto e limpeza urbana & 2,58 & $14^{\circ}$ & 4,17 & $30^{\circ}$ & 0,9 & $25^{\circ}$ \\
\hline
\end{tabular}


Tabela 4 - Multiplicadores de impacto do semiárido baiano, 2015

\begin{tabular}{|c|c|c|c|c|c|c|c|}
\hline & \multirow{3}{*}{ Setores de atividade econômica } & \multicolumn{2}{|c|}{ Produção } & \multicolumn{2}{|c|}{ Emprego } & \multicolumn{2}{|c|}{ Renda } \\
\hline & & \multicolumn{2}{|c|}{$\begin{array}{l}\text { Variação unitária - } \\
\text { (R\$) }\end{array}$} & \multicolumn{2}{|c|}{$\begin{array}{l}\text { Cada } R \$ 1 \text { milhão } \\
\text { na demanda final }\end{array}$} & \multicolumn{2}{|c|}{$\begin{array}{c}\text { Variação unitária - } \\
(\mathrm{R} \$)\end{array}$} \\
\hline & & $\mathrm{MPj}$ & Rank & Mej & Rank & $\mathrm{MVj}$ & Rank \\
\hline 31 & Construção civil & 2,07 & $24^{\circ}$ & 10,13 & $16^{\circ}$ & 1,03 & $14^{\circ}$ \\
\hline 32 & Comércio e serviços de manutenção e reparação & 1,5 & $36^{\circ}$ & 19,31 & $8^{\circ}$ & 1 & $18^{\circ}$ \\
\hline 33 & Transporte, armazenagem e correios & 1,9 & $27^{\circ}$ & 10,91 & $14^{\circ}$ & 0,91 & $23^{\circ}$ \\
\hline 34 & Serviços de alojamento e alimentação & 2,13 & $22^{\circ}$ & 15,52 & $10^{\circ}$ & 0,86 & $26^{\circ}$ \\
\hline 35 & Serviços de informação & 2,08 & $23^{\circ}$ & 10,1 & $17^{\circ}$ & 0,9 & $24^{\circ}$ \\
\hline 36 & Intermediação financeira e prev. complementar & 1,65 & $31^{\circ}$ & 3,88 & $31^{\circ}$ & 1 & $17^{\circ}$ \\
\hline 37 & Atividades imobiliárias e aluguéis & 1,15 & $40^{\circ}$ & 1,38 & $39^{\circ}$ & 1,07 & $11^{\circ}$ \\
\hline 38 & Serviços prestados às empresas & 1,57 & $33^{\circ}$ & 23,78 & $6^{0}$ & 1,12 & $9^{\circ}$ \\
\hline 39 & Adm. púb., saúde e educ. púb. e seguridade social & 1,38 & $38^{\circ}$ & 134,37 & $1^{\circ}$ & 1,02 & $16^{\circ}$ \\
\hline 40 & Saúde e educação mercantil & 1,57 & $32^{\circ}$ & 5,25 & $27^{\circ}$ & 0,97 & $19^{\circ}$ \\
\hline 41 & Serviços prestados às famílias & 1,53 & $35^{\circ}$ & 11,46 & $13^{\circ}$ & 1,05 & $13^{\circ}$ \\
\hline
\end{tabular}

Fonte: Elaborado pelos autores, 2018.

Os dados acima são interpretados da seguinte forma: para cada aumento de 1 unidade monetária na demanda final do setor exigem-se 4,06 unidades monetárias do produto de todos os setores da economia baiana, em 2015. Os setores de perfumaria, higiene e limpeza possuem o segundo maior multiplicador de produção e o de metalurgia e siderurgia o terceiro com maior impacto sobre a economia baiana naquele ano.

Nos setores com maiores multiplicadores de emprego, é possível fazer a relação: para cada 1 milhão de unidades monetárias dispendidas na demanda final, indica-se a quantidade de empregos gerados. Uma vez que se trata de contas, recomenda-se empregar números inteiros, pois se trata de empregos, mas como são empregos por valores monetários, é possível fazer essa conversão ao verificar os resultados dos impactos. Assim, no semiárido baiano, em 2015, para cada 1 milhão de unidades monetárias na demanda final, maior é o potencial do setor da administração pública para gerar empregos formais na economia. São 134 empregos totais (diretos e indiretos), aproximadamente. A esse setor, segue-se o de perfumaria, higiene e limpeza, que geraria 31 postos de trabalho totais, com o multiplicador. Já o setor de móveis e indústrias diversas, com multiplicador, atingiria 28 postos de trabalho formais totais na economia.

Os multiplicadores de renda indicam qual a variação da renda sobre a variação no componente da demanda final de determinado setor. Assim, no semiárido baiano, os setores de cultivo de cereais, o de cultivo de outras lavouras temporárias e o de maquinas e equipamentos e manutenção são os que apresentam maior destaque nesse quesito, o que mostra a força do setor agrícola da região para a geração de renda, como pôde ser observado na Tabela 4.

\section{Considerações finais}

A utilização dos indicadores de insumo-produto possibilitou compreender a estrutura produtiva do semiárido baiano. Por meio da análise estrutural dos índices de ligação Rasmussen-Hirschman e de dispersão, foram identificados os setores chave da região: 12 - outros da indústria extrativa, 13 alimentos, bebidas e fumo, 14 - têxtil, vestuário e artigos de couros, 18 - produtos químicos diversos, 21 
- indústria da borracha e do plástico, 23 - metalurgia e siderurgia, 30 - eletricidade, gás, água, esgoto e limpeza urbana. $\mathrm{Na}$ condição de demandantes de insumos e ofertantes de produtos, esses setores são de grande importância porque impactam os demais. Dessa forma, políticas que visem o desenvolvimento da região devem considerar as ligações intersetoriais. Com base nos campos de influência foi possível conhecer as ligações mais importantes da estrutura produtiva do semiárido, destacando-se os setores 29 móveis e indústrias diversas e 30 - eletricidade, gás, água, esgoto e limpeza urbana como os que apresentam maiores efeitos propagadores sobre os demais, na ótica das compras (nas colunas). Na ótica das vendas, há pouca interação.

A análise de impactos, realizada por meio dos multiplicadores, demonstrou que o setor 17 - álcool e biocombustíveis é o que mais se destaca na produção. O setor de maior potencial para gerar empregos formais na economia é o 39 - administração pública, com 134 empregos totais (diretos e indiretos), aproximadamente. A esse seguem-se o setor 19 - perfumaria, higiene e limpeza, que geraria 31 postos de trabalho totais, e o de móveis e indústrias diversas, com um total de 28 postos de trabalho formais na economia. Já nos multiplicadores de renda, destacam-se os setores 1 - cultivo de cereais, 5 - outras lavouras temporárias e 25 - máquina e materiais elétricos. Esses dados mostram o peso do setor agrícola para a geração de renda na região.

Assim, o formulador de políticas no processo de tomada de decisão deve estar atento ao objetivo que se deseja alcançar. Se for o crescimento econômico da região, os setores chave, identificados neste trabalho, deveriam ser o foco da política. Se a intenção é fomentar o desenvolvimento, devem-se observar os multiplicadores de emprego e renda. No entanto, se o propósito é verificar um indicador de crescimento, o multiplicador de produção seria mais adequado. Nesse sentido, ao avaliar a estrutura produtiva do semiárido baiano, espera-se contribuir com os agentes envolvidos na tomada de decisão para a elaboração de políticas visando o desenvolvimento social e econômico da região.

\section{Referências}

BACHARACH, M. Biproportional matrices and input-output change. Cambridge: Cambridge University Press, 1970.

BAHIA. Secretaria de Desenvolvimento Econômico (SDE). Energia Eólica. 2018.

Superintendência de Estudos Econômicos e Estatísticos (SEI). PIB Municipal. 2016.

BRASIL. Superintendência do Desenvolvimento do Nordeste (SUDENE). Delimitação do semiárido. 2018.

CABRAL, J. A.; CABRAL, M. V. F.; OLIVEIRA, D. R. Análise do conteúdo tecnológico das exportações brasileiras sob a lógica estruturalista-kaldoriana. Nova Economia, v.27, n. 2, p. 157-184, 2017. DIETZENBACHER, E.; VAN DER LINDEN, J. A.; STEENGE, A. E. The regional extraction method: EC input-output comparisons. Economic Systems Research, v. 5, n. 2, 1993.

GONÇALVES, M. F.; NEVES, M. C. R.; BRAGA, M. J. Análise da economia baiana em 2011 à luz da matriz insumo-produto. Nexos econômicos. Salvador, v. 8, n. 2, 2014. 
GUILHOTO, J. J. M. Input - Output Analysis: Theory and Foundations. FEA-USP. 2011.

GUILHOTO, J. J. M.; AZZONI, C. R.; ICHIHARA, S. M.; KADOTA, D. K.; HADDAD, E. A. Matriz de Insumo-Produto do Nordeste e Estados: Metodologia e Resultados. Fortaleza: Banco do Nordeste do Brasil, 2010.

HIRSCHMAN, A.O. The Strategy of Economic Development. Yale University Press. 1958.

LEITE, A.P.V. Uma metodologia para construção de matrizes regionais compatíveis - o RAS modificado agregado: uma aplicação para as grandes regiões do Brasil em 2006. Dissertação, Universidade Federal da Bahia, Salvador, 2009.

LEITE, A. P. V.; PEREIRA, R. M. Matriz insumo-produto da economia baiana: uma análise estrutural e subsídios às políticas de planejamento. Revista Desenbahia, v. 7, n. 13, 2010.

LOPES, P. R. C. Alternativas de manejo de solo e água para o Semiárido brasileiro. 2003.

Disponível em: www.comciencia.br/reportagens. Acesso em 03 de agosto de 2018.

MEDEIROS, S. de S. et al. Sinopse do Censo Demográfico para o Semiárido Brasileiro. Campina Grande: INSA, 2012.103p.

MILLER, R.E.; P.D. BLAIR. Input-Output Analysis: Foundations and Extensions. 2 ed. Cambrige: Cambridge University Press. 2009.

MYRDAL, G. Economic theory and under-developed regions. LTD:London, 1957.

NASCIMENTO, H. M. Semiárido Brasileiro e Baiano: dimensão territorial e estratégia de desenvolvimento. $48^{\circ}$ Congresso Sober, 2010.

PEREIRA, R. M. Aspectos econômicos dos modelos de cobrança da água pelo lançamento de efluentes: a bacia hidrográfica do rio Paraíba do Sul. UFBA, Salvador, 2007.

PEROBELlI, F. S.; VALE, V. A.; PIRES, M. M. SANTOS, J. P. C.; ARAÚJO JÚNIOR, I. F. Estimativa da matriz de insumo-produto da Bahia (2009): características sistêmicas da estrutura produtiva do estado.

Revista Econômica do Nordeste, Fortaleza, v. 46, n. 4, 2015.

PERROUX, F. A Economia do Século XX. Lisboa: Livraria Morais Editora, 1967. 755 p.

. Nota Sobre o Conceito de "Polo de Crescimento". In: PERROUX, F; FRIEDMANN, J; TINBERGEN, J. A Planificação e os Polos de Desenvolvimento. Porto: Edição Rés Limitada, p. 5-26, 1975. 82 p.

PRADO, E. F. S. Estrutura tecnológica e desenvolvimento regional. IPE/USP, 1981. 230 p.

RASMUSSEN, P. Studies in Intersectoral Relations. Amsterdam: North Holland. 1956. RIBEIRO, C. S; OLIVEIRA, G. G. The water question in the bahian semi-arid and the social technologies for the use of rainwater. Revista del Cesla, n. 23, 2019.

RIBEIRO, L. C. S.; ROCHA, G. B. Interdependência produtiva e estratégias de desenvolvimento para o estado da Bahia. Economia Ensaios, v. 27, n. 2, p. 67-83, 2013.

SILVA, R. M. A. Entre o combate à seca e a convivência com o Semiárido: transições paradigmáticas e sustentabilidade do desenvolvimento. 2006. 298p. Tese de Doutorado - Centro de Desenvolvimento Sustentado, Universidade de Brasília. 
SILVEIRA, A. H. P. Uma variante do método biproporcional para a estimativa de matrizes de relações intersetoriais na ausência de dados sobre produção intermediária. In: Congresso Nacional de Economia, Anais... Belo Horizonte: ANPEC, 1993.

SONIS, M.; HEWINGS, G.J.D. Error and Sensitivity Input-Output Analysis: a New Approach. In: R.E. Miller, K.R. Polenske e A.Z. Rose (eds.) Frontiers of Input-Output Analysis. New York, Oxford University Press. 1989.

Fields of Influence in Input-Output Systems. University of Illinois, Regional Economics Applications Laboratory, 1994.

STONE, R. Input-output and demographie accouting: a tool for education planning. Minerva, v. 4, n. 3, p. 365-380, 1962.

\section{Apêndices}

1. Matriz de insumo-produto do semiárido baiano - 2015 - Matriz A

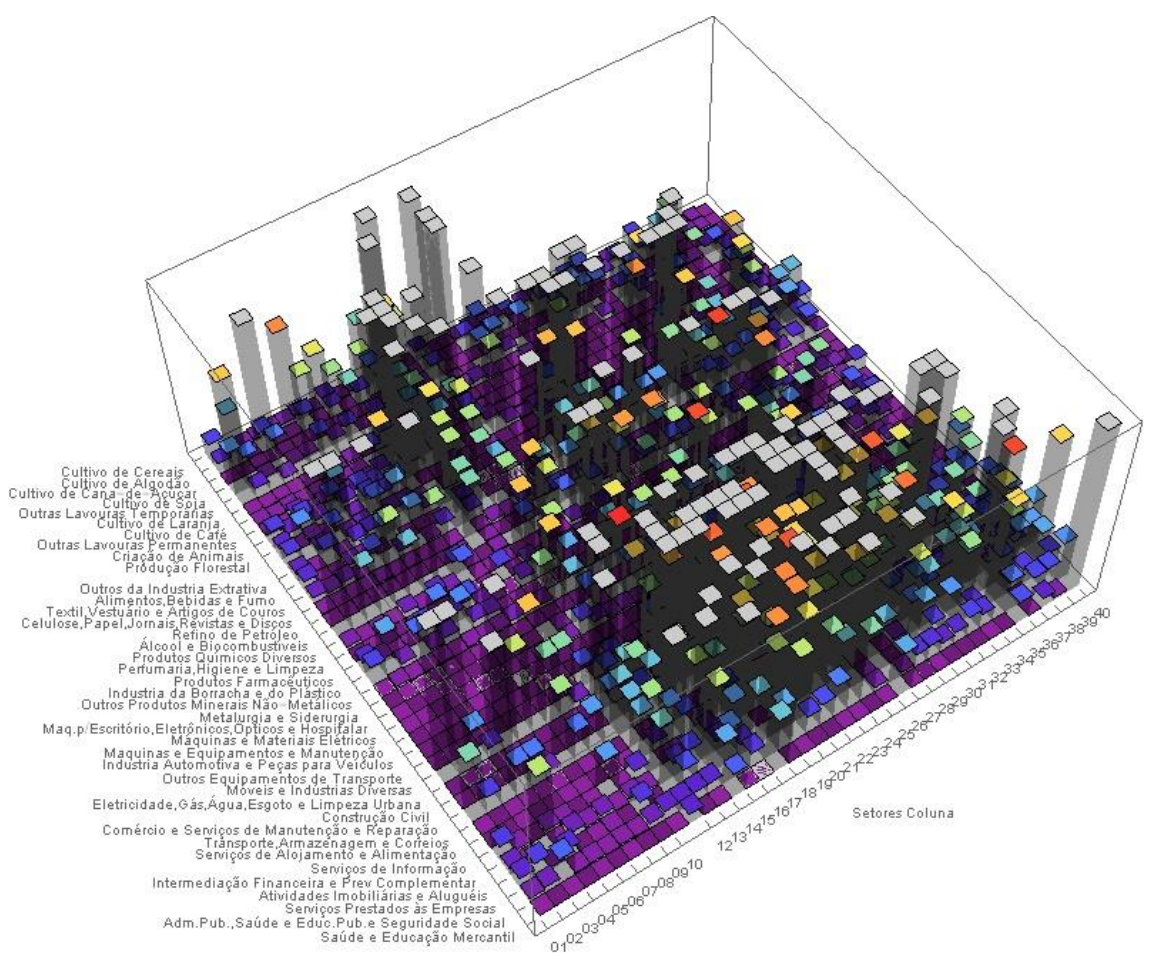

2. Matriz de insumo-produto do semiárido baiano - 2015 - Matriz de impactos indiretos 


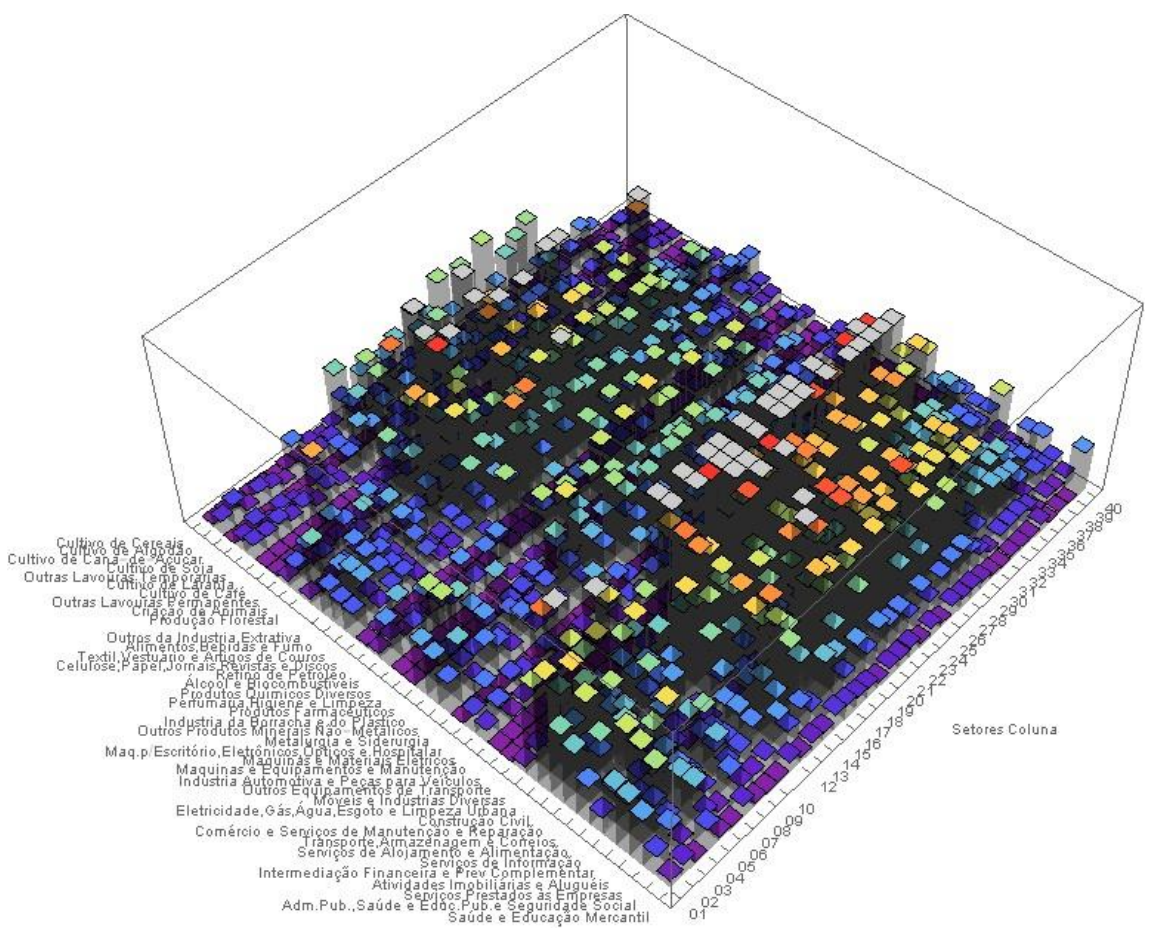

3. Matriz de insumo-produto do semiárido baiano - 2015 - Matriz B, Inversa de Leontief.

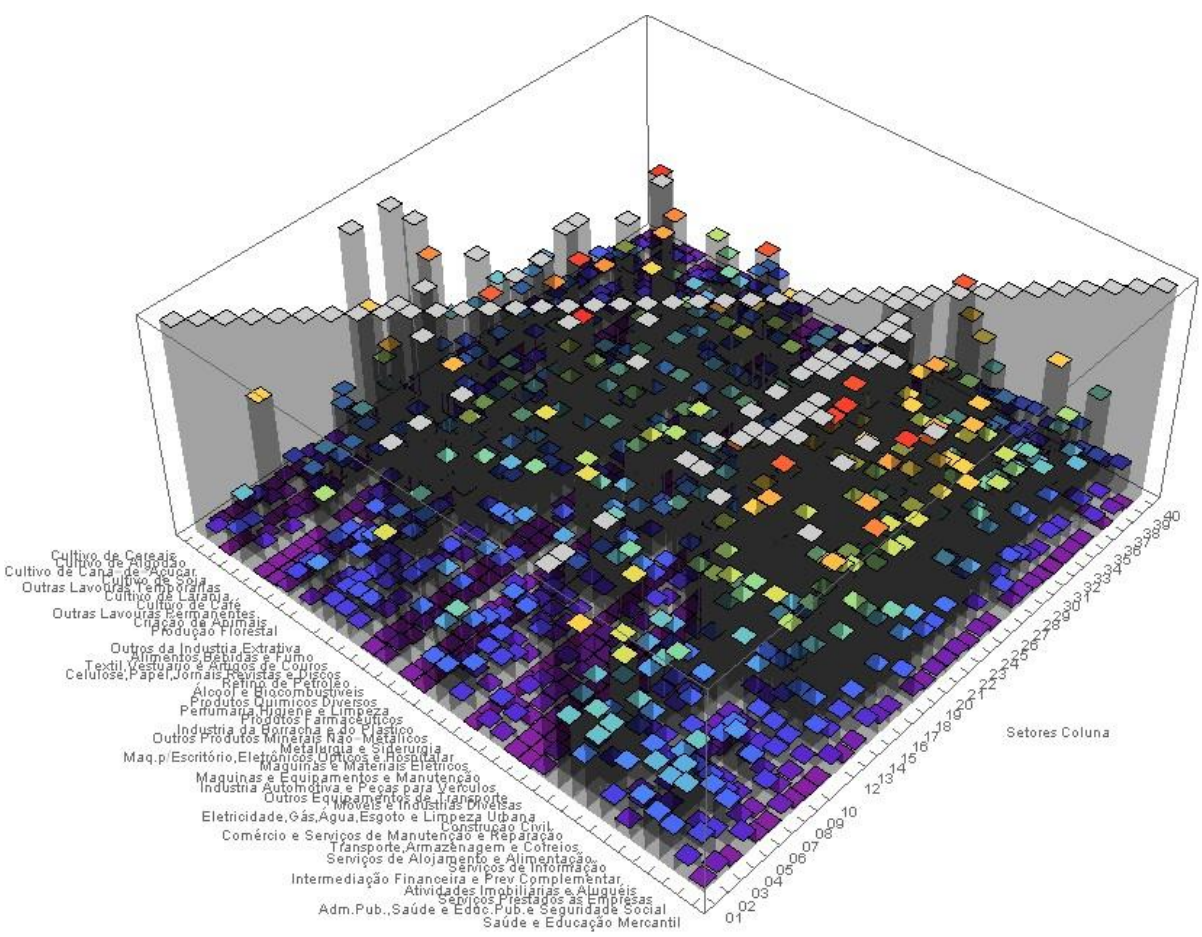

Recebido em: setembro de 2020.

Aprovado em: novembro de 2020. 